\title{
STUDI PENATAAN KAWASAN WISATA BUKIT PANYAWEUYAN DENGAN KONSEP AGROWISATA (LOKASI: BUKIT PANYAWEUYAN, DESA TEJAMULYA, KECAMATAN ARGAPURA, KABUPATEN MAJALENGKA, JAWA BARAT)
}

\author{
Eko Mujiarto ${ }^{1)}$, Priyendiswara $\mathrm{AB}^{2)}$, Bambang Deliyanto ${ }^{3)}$, B. Irwan Wipranata ${ }^{4)}$
}

\footnotetext{
1)Program Studi S1 PWK, Fakultas Teknik, Universitas Tarumanagara, ekomujiarto92@gmail.com

2)Program Studi S1 PWK, Fakultas Teknik, Universitas Tarumanagara, priyendiswaraa@ft.untar.ac.id

3)Program Studi S1 PWK, Fakultas Teknik, Universitas Tarumanagara, deli.bambang@gmail.com

4)Program Studi S1 PWK, Fakultas Teknik, Universitas Tarumanagara, irwan_wiparanata@yahoo.uk
}

\begin{abstract}
Abstrak
Tulisan ini merupakan hasil penelitian yang dilakukan oleh penulis dan dituangkan dalam Tugas Akhir, dimana judul penelitian ini yaitu Penataan Kawasan Wisata Bukit Panyaweuyan dengan Konsep Agrowisata. Lokasi penelitian ini yaitu di Desa Tejamulya, Kecamatan Argapura, Kabupaten Majalengka, Provinsi Jawa Barat. Adapun tujuan dari penelitian ini yaitu membuat masterplan kawasan wisata Bukit Panyaweuyan yang dilihat dari kebijakan terkait objek studi, kondisi eksisting lokasi dan tapak, komponen agrowisata, kegiatan wisata yang ada, persepsi dan preferensi pengunjung dan best practice dari objek lain yang serupa. Untuk mencapai tujuan tersebut maka dilakukan beberapa analisis dengan menggunakan alat analisis seperti deskriptif, dan diagram kartesisus. Sehingga hasil dari analisis tersebut dapat digunakan untuk membuat masterplan kawasan wisata Bukit Panyaweuyan.
\end{abstract}

Kata Kunci: Agrowisata; Bukit Panyaweuyan; Masterplan; Penataan Kawasan

\begin{abstract}
This paper is the result of research conducted by the author and set forth in the Final Project, where the title of this research is "the Panyaweuyan Hill Tourism Area Structuring with the Concept of Agrotourism". The location of this research is in the village of Tejamulya, Argapura District, Majalengka Regency, West Java Province. The purpose of this research is to make the Bukit Panyaweuyan tourist area masterplan as seen from the policies related to the object of study, the existing condition of the site and site, the agro tourism component, existing tourism activities, visitor perceptions and preferences and best practices of other similar objects. To achieve these objectives, several analyzes are carried out using analytical tools such as descriptive, and cartesian diagrams. So the results of the analysis can be used to make the Panyaweuyan Bukit tourism area masterplan.
\end{abstract}

Keywords: Agro Tourism, Masterplan, Panyaweuyan Hill, Regional Arrangement

\section{PENDAHULUAN}

Pariwisata di Indonesia memiliki beragam pariwisata yang dimana menjadi dominan adalah Pariwisata Alam, Budaya, dan Kuliner. Pariwisata Alama yang menjadi pembahasan utama, terdiri dari beberapa tipe yaitu Wisata Bahari dan Wisata Cagar Alam. Wisata Bahari adalah wisata seperti pantai, laut, danau, dan Olahraga Air. Sedangkan Wisata Cagar Alam adalah Wisata hayati seperti hutan, pegunungan, bukit, perkebunan, dan kebun binatang.

Provinsi Jawa Barat memiliki beragam pariwisata seperti wisata bahari dan wisata cagar alam. Wisata bahari adalah wisata seperti pantai, laut, danau dan olahraga air. Sedangkan wisata cagar 
alam adalah wisata hayati seperti hutan, pegunungan, bukit, perkebunan, dan kebun binatang. Pariwisata memiliki peran yang sangat penting dalam sektor ekonomi, yang dimana dengan adanya sektor pariwisaata dapat membantu meningkatkan pendapatan asli daerah (PAD).

Dikutip dari Rencana Induk Pengembangan Pariwisata Daerah Kabupaten Majalengka Tahun 2010, DISPARBUD memiliki visi dengan kurun waktu tahun 2010-2025 yaitu: Mewujudkan Kabupaten Majalengka sebagai destinasi ekowisata alam agro dan seni budaya yang berdaya saing dan berkelanjutan, serta berbasis masyarakat yang beriman dan bertaqwa tahun 2025 . Untuk mencapai Visi tersebut, maka Disparbud Kabupaten Majalengka menetapkan misi sebagai berikut:

a. Membangun destinasi pariwisata alam agro dan seni budaya yang berdaya saing internasional melalui perlindungan, pengembangan dan pengelolaan terhadap sumber daya wisata alam pegunungan, pertanian, serta seni budaya tradisional dan kontemporer yang mendukung kepariwisataan Kabupaten Majalengka secara berkelanjutan.

b. Membangun dan mengembangkan industri pariwisata kreatif yang berpihak pada masyarakat lokal, berdaya saing, dan berbudaya, sekaligus mengembangkan jejaring industri secara nasional dan internasional untuk mendukung perekonomian Kabupaten Majalengka.

c. Mengembangkan pemasaran dan promosi pariwisata yang bertanggung jawab dan terpadu dengan sektor ekonomi lain di Kabupaten Majalengka, dan dengan destinasi pariwisata lainnya di Jawa Barat maupun nasional.

d. Membangun dan meningkatkan sistem kelembagaan kepariwisataan serta memberdayakan SDM lokal yang beriman dan bertaqwa untuk memperkuat peran masyarakat dalam pembangunan kepariwisataan Kabupaten Majalengka.

Bukit Panyaweuyan terletak di desa Tejamulya, Kecamatan Argapura, Kabupaten Majalengka, Provinsi Jawa Barat. Bukit Panyaweuyan merupakan salah satu Bukit di Desa Tejamulya yang dijadikan tujuan wisata dikarnakan masih sangat bersih dan alami. Bukit Panyaweuyan memiliki keindahan alam yang eksotis dimana para wisatawan dimanjakan oleh pemandangan hamparan perkebunan di atas bukit yang sangat indah.

Namun Keindahan Wisata Bukit Panyaweuyan masih diperlukan perencanaan penataan yang lebih baik lagi khususnya fasilitas, sarana dan prasarana, dan aksesbilitas. Kurangnya fasilitas pendukung seperti area parkir, pos keamanan, jalur evakuasi di Kawasan wisata Bukit Panyaweuyan, dan mempertahankan prinsip untuk tetap menjadi area agrowisata. Bukit Panyaweuyan jika terus dikembangkan dan ditata dengan baik akan meningkatkan daya tarik yang dapat meningkatkan perekonomian masyarakat sekitar Kawasan Wisata Bukit Panyaweuyan. Atas dasar tersebut, maka Bukit Panyaweuyan ini dapat dilakukan rencana penataan pada kawasan tersebut.

\section{Rumusan Masalah}

Rumusan Masalah dalam penelitian ini adalah masih kurangnya sarana dan prasarana penunjang di Bukit Panyaweuyan seperti Infrastruktur (akses) menuju kawasan wisata, belum tersedianya fasilitas - fasilitas umum, dan tidak adanya akomodasi yang mendukung untuk menuju kawasan wisata.

\section{Tujuan Penelitian}

Tujuan Penelitian ini adalah untuk membuat rencana penataan wisata Bukit Panyaweuyan dengan tetap menjaga sistem perkebunan dan keberlanjutan objek wisata dengan konsep Agrowisata. Sedangkan tujuan khusus penelitian yaitu: 
a. Mengetahui cara memanfaatkan potensi Bukit Panyaweuyan yang sudah ada dengan baik namun tetap menjaga sistem perkebunannya.

b. Mengetahui Sarana, Prasarana dan Fasilitas Pendukung yang dibutuhkan untuk mendukung kegiatan wisata dan meningkatkan perekonomian masyarakat sekitar Bukit Panyaweuyan.

c. Mengetahui potensi dari Kawasan wisata yang dapat diusulkan dalam pembuatan rencana masterplan untuk penataan kawasan wisata Bukit Panyaweuyan.

\section{KAJIAN LITERATUR}

\section{Pengertian Agrowisata}

Menurut Maruti (2009), sebuah agrowisata adalah pariwisata yang pro pertanian, bisnis berbasis usahatani yang terbuka untuk umum. Tavare dalam Maruti, 2009 mendefinisikan agrowisata sebagai aktivitas agribisnis dimana petani setempat menawarkan tur pada usahataninya dan mengijinkan seseorang pengunjung menyaksikan pertumbuhan, pemanenan, pengolahan pangan lokal yang tidak akan ditemukan di daerah asalnya. Sering petani tersebut menyediakan kesempatan kepada pengunjung untuk tinggal sementara dirumahnya dan program pendidikan.

\section{Pengelompokan dan Prinsip Agrowisata}

Menurut Bappenas (2004), kawasan agrowisata merupakan suatu kawasan yang memiliki kriteria sebagai berikut:

a. Memiliki potensi atau basis kawasan di sektor agro baik pertanian, hortikultura, perikanan maupun peternakan, misalnya:

1) Subsistem usaha pertanian primer (on farm) yang antara lain terdiri dari pertanian tanaman pangan dan hortikultura, perkebunan, perikanan, peternakan dan kehutanan;

2) Subsistem industri pertanian yang antara lain terdiri industri pengolahan, kerajinan, pengemasan, dan pemasaran baik lokal maupun ekspor;

3) Subsistem pelayanan yang menunjang kesinambungan dan daya dukung kawasan baik terhadap industri dan layanan wisata maupun sektor agro, misalnya transportasi dan akomodasi, penelitian dan pengembangan, perbankan dan asuransi, fasilitas telekomunikasi, dan infrastruktur;

b. Adanya kegiatan masyarakat yang didominasi oleh kegiatan pertanian dan wisata dengan keterkaitan dan kebergantungan yang cukup tinggi, antara lai kegiatan pertanian yang mendorong tumbuhnya industri pariwisata, dan sebaliknya kegiatan pariwisata yang memacu berkembangnya sektor pertanian;

c. Adanya interaksi yang intensif dan saling mendukung bagi kegiatan agro dengan kegiatan pariwisata dalam kesatuan kawasan, antara lain berbagai kegiatan dan produk wisata yang dikembangkan secara berkelanjutan.

\section{Komponen dan Kriteria Agrowisata}

Menurut Moore (2005) unsur-unsur penting yang menjadi acuan dalam pengembangan menggunakan konsep agrowisata adalah:

a. Konservasi

Kekayaan keanekaragaman hayati merupakan daya tarik utama bagi pangsa pasar agrowisata sehingga kualitas, keberlanjutan dan pelestarian sumber daya alam, peninggalan sejarah dan budaya sangatlah penting untuk pengembangan agrowisata.

b. Masyarakat dan Lembaga

Pada dasarnya pengetahuan tentang alam dan budaya serta daya tarik wisata kawasan dimiliki oleh masyarakat setempat, oleh karena itu pelibatan masyarakat setempat menjadi mutlak, mulai dari tingkat perencanaan hingga pada tingkat pengelolaan. 
Pengembangan agrowisata juga tidak luput dari kelembagaan yang pada pengembangan lebih banyak dimotori oleh lembaga swadaya masyakarat, pengabdi masyarakat dan lingkungan. Hal ini lebih banyak didasarkan oleh komitmen terhadap upaya pelestarian lingkungan, pengembangan ekonomi dan pemberdayaan masyarakat secara berkelanjutan.

c. Pendidikan

Agrowisata meningkatkan kesadaran dan apresiasi terhadap alam, nilainilai peninggalan sejarah dan budaya. Agrowisata memberikan nilai tambah bagi pengunjung, masyarakat dan pengembang pariwisata agar sadar dan lebih menghargai alam, nilai-nilai peninggalan sejarah dan budaya.

d. Pasar

Kenyataan memperlihatkan kecenderungan meningkatnya permintaan terhadap produk agrowisata baik ditingkat internasional maupun nasional. Hal ini disebabkan oleh meningkatnya promosi yang mendorong orang untuk berperilaku positif terhadap alam.

e. Ekonomi

Agrowisata memberikan peluang bagi penyelenggara, pemerintah, dan masyarakat sekitar, melalui kegiatan yang non ekstraktif, sehingga meningkatkan perekonomian daerah setempat.

\section{METODE}

Data yang akan dikumpulkan selama proses penelitian adalah data yang sesuai dengan kebutuhan yang meliputi jenis data dan Teknik pengumpulan data. Teknik pengumpulan data yang dilakukan dalam penelitian ini terbagi atas metode pengumpulan data primer dan pengumpulan data sekunder. Untuk metode pengumpulan data primer dilakukan dengan observasi/survei lapangan dan wawancara dengan pihak - pihak terkait. Sementara untuk metode pengumpulan data sekunder dilakukan dengan dokumentasi dan studi literatur Seperti Peraturan kebijakan yang terkait dengan wisata Kabupaten Majalengka, Dokumentasi dan data pendukung terkait wisata Bukit Panyaweuyan, Data Makro Kabupaten Majalengka, BPS Kabupaten Majalengka, BPS Kecamatan Argapura.

Untuk analisis yang dilakukan dalam penelitian ini adalah analisis kebijakan untuk mendalami informasi sehingga menghasilkan rekomendasi kebijakan publik merupakan keputusan dari pemerintah yang berpengaruh terhadap individu dalam kelompok masyarakat, analisis tapak, analisis lokasi, analisis best practice, analisis komponen konsep agrowisata, analisis kegiatan wisata, analisis presepsi \& preferensi, analisis kebutuhan ruang.dan secara keseluruhan alat analisis menggunakan metode crosstab dan IPA yang dimana untuk melihat hubungan antara variable satu dengan yang lainnya mengenai preferensi pengunjung yang berkunjung ke kawasan Wisata Bukit Panyaweuyan.

\section{HASIL DAN PEMBAHASAN}

\section{Analisis Kebijakan}

Analisis kebijakan yang penulis lakukan pada penelitian ini meninjau peraturan pemerintah yang tercantum dalam Rencana Induk Pembangunan Kepariwisataan (RIPPARPROV), dan Rencana Tata Ruang Wilayah (RTRW).

\section{Rencana Induk Pembangunan Kepariwisataan Provinsi Jawa Barat (RIPPARPROV) Tahun 2015 $-2025$}

Berdasarkan Peraturan Daerah Provinsi Jawa Barat No. 15 Tahun 2015 Tentang Rencana Induk Pembangunan Kepariwisataan Provinsi Jawa Barat (RIPPARPROV), memiliki visi menjadikan 
Jawa Barat sebagai destinasi pariwisata berkelas dunia yang terintegrasi, berkelanjutan, dan menjunjung tinggi nilai budaya. Dalam mewujudkan visi tersebut maka ditempuh 4 misi yaitu membangun destinasi pariwisata berkelas dunia, struktur industri yang kuat dan terintegrasi, pemasaran yang efektif, kelembagaan kepariwisataan yang mampu meningkatkan integrasi pembangunan. Visi misi tersebut diwujudkan dalam kebijakan pembangunan destinasi pariwisata. Dalam kebijakan tersebut diatur juga terkait kebijakan Kabupaten Majalengka sebagai berikut :

Tabel 1. Kebijakan Terkait Kabupaten Majalengka dalam RIPPARPROV Jawa Barat 2015 - 2025

\begin{tabular}{lll}
\hline No & Pasal, Ayat & \multicolumn{1}{c}{ Kebijakan } \\
\hline 1 & $\begin{array}{l}\text { Pasal 27, ayat 1 } \\
\text { (f) }\end{array}$ & $\begin{array}{l}\text { Kabupaten Majalengka termasuk dalam KPPP (Kawasan Pengembangan } \\
\text { Pariwisata Provinsi) meliputi Kawasan Ekowisata Alam Pegunungan } \\
\text { Majalengka- Kuningan dan sekitarnya. }\end{array}$ \\
\hline \multirow{2}{*}{ Pasal 33 (a) } & $\begin{array}{l}\text { Rencana pembangunan KPPP Kawasan Ekowisata Alam Pegunungan } \\
\text { Majalengka- Kuningan dan sekitarnya memiliki tema pengembangan } \\
\text { ekowisata dan pegunungan }\end{array}$ \\
\hline 3 & Pasal 33 (b) & Kabupaten Majalengka termasuk dalam daya tarik wisata primer \\
\hline
\end{tabular}

Sumber : RIPPARPROV Jawa Barat 2015 - 2025

\section{Peraturan RTRW (daerah rawan bencana)}

Berdasarkan Peraturan daerah Kabupaten Majalengka No. 11 Tahun 2011 Tentang Rencana Tata Ruang Wilayah Kabupaten Majalengka Tahun 2011-2031, diketahui prioritas pelaksanaan pembangunan terdiri dari 4 komponen utama yaitu penataan wilayah, struktur ruang dan pola ruang wilayah dan Penetapan Kawasan Strategis.

1. Strategi Penataan Ruang Wilayah Kabupaten Majalengka

Dalam RTRW Kabupaten Majalengka 2011 - 2031 Bab III terdapat tujuan, kebijakan serta strategi penataan ruang wilayah Kabupaten Majalengka yang dilihat dari potensi lingkungannya. Berikut kebijakan penataan ruang yang telah diringkas dari Perda RTRW Kabupaten Majalengka yang menjadi dasar untuk penataan kawasan wisata bukit Panyaweuyan dengan konsep Agrowisata :

a. Pemantapan sistem agribisnis;

b. Pengembangan kegiatan wisata dengan memanfaatkan potensi alam;

c. Pengembangan pusat pelayanan sesuai dengan daya dukung dan daya tampung lingkungan.

2. Rencana Struktur Ruang Wilayah Kabupaten Majalengka

Dalam RTRW Kabupaten Majalengka 2011 - 2031 Bab IV, dapat dilihat rencana struktur ruang untuk melihat sistem pusat kegiatan maupun jaringan sistem prasarana umum yang akan dikembangkan. Berikut merupakan rencana sistem perkotaan yang akan dilakukan Kabupaten Majalengka untuk Kecamatan Argapura: Kecamatan Argapura sebagaimana dimaksud dalam pasal ayat huruf memiliki fungsi utama sebagai pusat pelayanan sosial dan umum, pengembangan pertanian dan peternakan, komersial, pengembangan pariwisata, pengembangan kawasan perkotaan, terminal regional, perikanan, dan industri kecil.

3. Rencana Pola Ruang Kabupaten Majalengka

Dalam RTRW Kabupaten Majalengka tahun 2011-2031 Bab V, terdapat Rencana Pola Ruang yang membahas mengenai Kecamatan Argapura terutama kawasan wisata Bukit Panyaweuyan, yaitu :

a. Pasal 22 ayat 4 disebutkan Kecamatan Argapura sebagai Kawasan sekitar mata air yang meliputi mata air kontinu (terus mengalir), mata air yang mengalir 9 bulan, dan mata air yang mengalir 6 bulan. 
b. Pasal 24 ayat 2 disebutkan Kecamatan Argapura sebagai Kawasan Rawan Bencana tanah longsor.

c. Pasal 25 ayat 3 disebutkan Kecamatan Argapura sebagai Kawasan Rawan Gerakan Tanah.

d. Pasal 25 ayat 4 disebutkan Kecamatan Argapura sebagai Kawasan Bencana Gunung Berapi.

e. Pasal 25 ayat 5 disebutkan Kecamatan Argapura sebagai Kawasan Gempa Bumi.

f. Pasal 29 ayat 3 disebutkan Kecamatan Argapura sebagai Kawasan Peruntukan Pertanian Lahan Basah berupa lahan pertanian pangan berkelanjutan yang terdiri atas sawah irigasi setengah teknis dan sawah tadah hujan.

g. Pasal 29 ayat 6 disebutkan Kecamatan Argapura sebagai Kawasan Peruntukkan Perkebunan yang meliputi kawasan peruntukkan fungsi lindung.

h. Pasal 31 ayat 2 disebutkan kecamatan Argapura sebagai Kawasan Peruntukkan Mineral dan Batuan meliputi logam berupa emas, batuan beku.

i. Pasal 33 ayat 3 disebutkan kawasan curug muara jaya dan sekitarnya yang terdapat di Kecamatan Argapura merupakan Kawasan Peruntukkan Pariwisata alam.

\section{Analisis Lokasi}

Kawasan Wisata Bukit Panyaweuyan sebagai objek studi terletak di Desa Tejamulya. Desa ini merupakan Wilayah administrasi dari Kecamatan Argapura, Kabupaten Majalengka, Jawa Barat. Jarak area penataan kawasan Bukit Panyaweuyan dari ibu kota Majalengka adalah $\pm 18 \mathrm{Km}$ dan apabila ditempuh dari sarana transportasi darat utama dan untuk menuju ke Kabupaten Majalengka berjarak $\pm 26 \mathrm{Km}$ dari Terminal Raja Galuh. area penataan kawasan adalah $\pm 39,50$ $\mathrm{Ha}$, Berikut ini adalah batas - batas kawasan Wisata Bukit Panyaweuyan :

- Sebelah Utara : Pertanian

- Sebelah Timur : Bukit Mercury

- Sebelah Selatan : Pertanian

- Sebelah Barat : Pertanian

\section{Jenis Tanah}

Analisis Jenis Tanah ini bertujuan untuk mengidentifikasi jenis tanah yang ada di dalam tapak kawasan perencaaan dan potensi serta keterbatasan jenis tanah tersebut. Berdasarkan peta jenis tanah yang didapat dari RTRW Kabupaten Majalengka tahun 2011 - 2031, jenis yang terdapat di dalam tapak kawasan Bukit Panyaweuyan adalah Tanah berjenis andosol. Berikut peta jenis tanah di kawasan Bukit Panyaweuyan beserta gambar tanahnya.

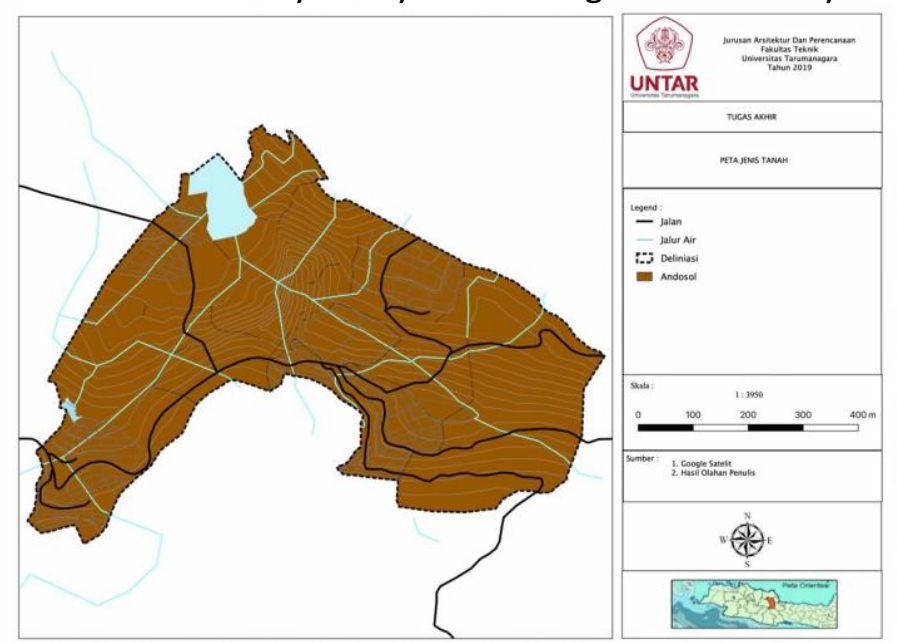

Gsmbar 1. Peta Analisis Jenis tanah di Kawasan Bukit Panyaweuyan Sumber: Olahan Penulis 
Tabel 2. Syarat Penanaman Buah berdasarkan Karakteristik Geografis

\begin{tabular}{|c|c|c|c|c|c|}
\hline No & Nama Buah & Syarat umum penanaman & Suhu & $\begin{array}{l}\text { Curah } \\
\text { hujan }\end{array}$ & $\begin{array}{c}\text { Ketinggi } \\
\text { an } \\
\text { lahan }\end{array}$ \\
\hline 1. & $\begin{array}{c}\text { Kesemek } \\
\text { Puspita, S. P. (2007). } \\
\text { Seri Budi Daya } \\
\text { Kesemek. Yogyakarta: } \\
\text { Kanisius (Anggota } \\
\text { IKAPI). }\end{array}$ & $\begin{array}{c}\text {-Tanah lembab kering } \\
\text {-Tanah subur } \\
\text {-Lahan terbuka } \\
\text {-Memiliki ketahanan pada suhu } \\
\text { panas } \\
\text {-Cocok di tanah loam, sandy loam } \\
\text { (tanah lempung berpasir) }\end{array}$ & $\begin{array}{l}18^{\circ}- \\
30^{\circ} \mathrm{C}\end{array}$ & $\begin{array}{c}300- \\
1000 \mathrm{~mm} / \mathrm{ta} \\
\text { hun }\end{array}$ & $\begin{array}{c}800- \\
1300 \mathrm{md} \\
\mathrm{pl}\end{array}$ \\
\hline 2. & $\begin{array}{c}\text { Apel } \\
\text { (https://kpricitrus.wor } \\
\text { dpress.com/2013/11/1 } \\
\text { 1/panduan-budidaya- } \\
\text { apel-di-indonesia/) }\end{array}$ & $\begin{array}{c}\text {-Lahan berlereng } \\
\text {-Tanah gembur } \\
\text {-Sistem penyerapan air yang baik } \\
\text {-Kedalaman air sampai } 2 \mathrm{~m} \\
\text {-Cocok di tanah regosol, } \\
\text { andosol,latosol }\end{array}$ & $\begin{array}{l}16^{\circ}- \\
27^{\circ} \mathrm{C}\end{array}$ & $\begin{array}{c}1000- \\
2600 \mathrm{~mm} / \mathrm{ta} \\
\text { hun }\end{array}$ & $\begin{array}{c}\text { 700- } \\
\text { 1200md } \\
\mathrm{pl}\end{array}$ \\
\hline 3. & $\begin{array}{c}\text { Stroberi } \\
\text { (http://budidaya- } \\
\text { petani.blogspot.co.id/2 } \\
\text { 013/02/budidaya- } \\
\text { tanaman-stroberi- } \\
\text { lengkap.html) }\end{array}$ & $\begin{array}{c}\text {-Tanah gembur } \\
\text {-Tanah liat berpasir } \\
\text {-Sistem drainase yang baik } \\
\text {-Kedalaman air } 50-100 \mathrm{~cm} \\
\text {-Hampir semua jenis tanah }\end{array}$ & $\begin{array}{l}17^{\circ}- \\
25^{\circ} \mathrm{C}\end{array}$ & $\begin{array}{c}600- \\
700 \mathrm{~mm} / \mathrm{tah} \\
\text { un }\end{array}$ & $\begin{array}{c}\text { 1000- } \\
\text { 1500md } \\
\text { pl }\end{array}$ \\
\hline 4. & $\begin{array}{c}\text { Alpukat Guatemala } \\
\text { (http://www.ruangtani } \\
\text {.com/10-panduan- } \\
\text { lengkap-teknik-dan- } \\
\text { cara-budidaya-buah- } \\
\text { alpukat-berkualitas- } \\
\text { tinggi/) }\end{array}$ & $\begin{array}{c}\text {-Tanah gembur } \\
\text {-Subur } \\
\text {-Sistem drainase baik } \\
\text { - Kedalaman air sampai } 2 \mathrm{~m} \\
\text {-Cocok di tanah sandy loam, clay } \\
\text { loam dan aluvial loam }\end{array}$ & $\begin{array}{l}15^{\circ}- \\
30^{\circ} \mathrm{C}\end{array}$ & $\begin{array}{c}750- \\
1000 \mathrm{~mm} / \text { ta } \\
\text { hun }\end{array}$ & $\begin{array}{c}\text { 1000- } \\
\text { 2000md } \\
\text { pl }\end{array}$ \\
\hline
\end{tabular}

Berdasarkan tabel syarat penanaman buah diatas dapat dilihat bahwa objek studi kawasan Bukit Panyaweuyan berpotensi untuk budidaya agrowisata dengan jenis tanaman buah - buahan diatas. Sementara dari hasil survey penulis, pada saat ini kondisi eksisting di dalam dan sekitar tapak adalah kawasan petanian sayur - sayuran yang hasil taninya seningkali di distribusikan ke luar kota, karena sayur - sayuran dari desa Tejamulya ini memiliki hasil yang khas dan segar.

\section{Kontur Tanah dan Kemiringan Lereng}

Berdasarkan hasil survey serta data kontur dan kemiringan berupa peta yang didapat dari RTRW Kabupaten Majalengka tahun 2011 - 2031 bahwa dapat dilihat dari segi topografinya, kondisi tanah di dalam kawasan memiliki kecenderungan menanjak dengan titik terendah $1037 \mathrm{mdpl}$ disisi utara dan tertinggi $1225 \mathrm{mdpl}$ di sisi Selatan, atau memiliki rentang kontur sekitar 188m antara titik tertinggi dan terendah, kontur tanah di dalam kawasan terbilang cukup curam dan konsisten mengalami peningkatan ketinggian dan bergelombang, dengan perbedaan ketinggian yang tidak terlalu signifikan di area tengah. Kemiringan tanah pada sisi utara berkisar antara 21$55 \%$ dan di sisi selatan relatif memiliki kemiringan yang sama yaitu sekitar $21-25 \%$ dan pada batas wilayah objek sebelah selatan $>55 \%$. Sedangkan pada area inti atau pusat objek studi memiliki kemiringan yaitu sekitar $21-30 \%$, berdasarkan teori lahan ini dapat dibangun untuk kebutuhan fasilitas penunjang dan beberapa wahana wisata. 


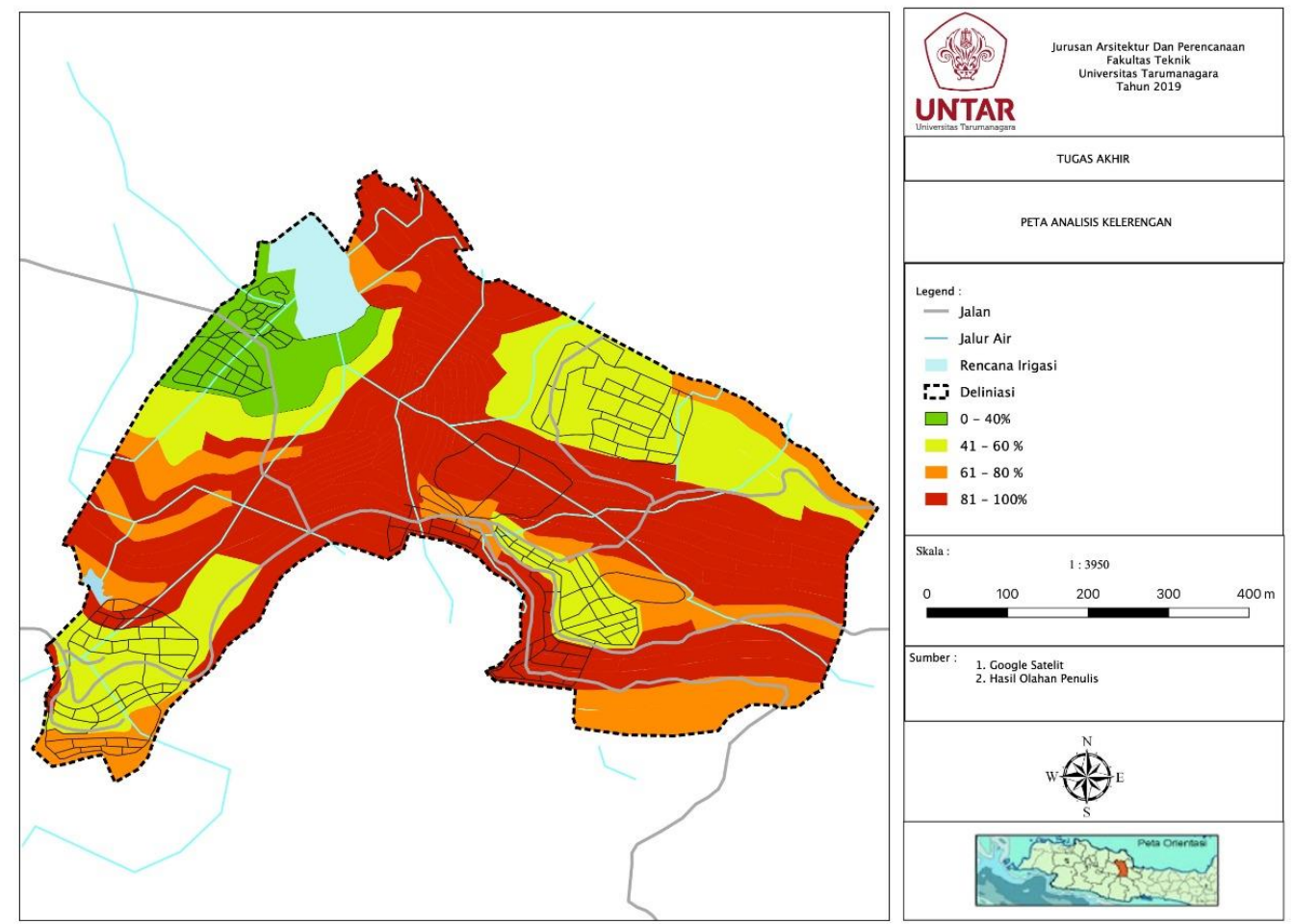

Gambar 2. Peta Kemiringan Lereng Tapak

Sumber: Hasil survey dan penghitungan penulis

\section{Proyeksi Pengunjung}

Berdasarkan data kunjungan wisatawan ke Kabupaten Majalengka yang diperoleh dari Dinas Pariwisata dan Kebudayaan Provinsi Jawa Barat, diketahui bahwa pertumbuhan pengunjung di Kabupaten Majalengka setiap tahunnya mengalami peningkatan. Berikut merupakan proyeksi pengunjung kawasan wisata Bukit Panyaweuyan dalam 10 tahun kedepan yang dihitung dengan metode geometric.

Tabel 3. Proyeksi Pengunjung Kawasan Wisata Bukit Panyaweuyan

\begin{tabular}{cc}
\hline Tahun & Jumlah Pengujung \\
\hline 2016 & 35,182 \\
\hline 2017 & 39,681 \\
\hline 2018 & 45,871 \\
\hline 2019 & 55,678 \\
\hline 2020 & 59,896 \\
\hline 2021 & 68,417 \\
\hline 2022 & 78,151 \\
\hline 2023 & 89,270 \\
\hline 2024 & 101,971 \\
\hline 2025 & 116,478 \\
\hline 2026 & 133,050 \\
\hline 2027 & 151,979 \\
\hline 2028 & 173,601 \\
\hline 2029 & 198,300 \\
\hline 2030 & 226,512
\end{tabular}

Sumber: Dinas Pariwisata dan Kebudayaan Provinsi Jawa Barat 


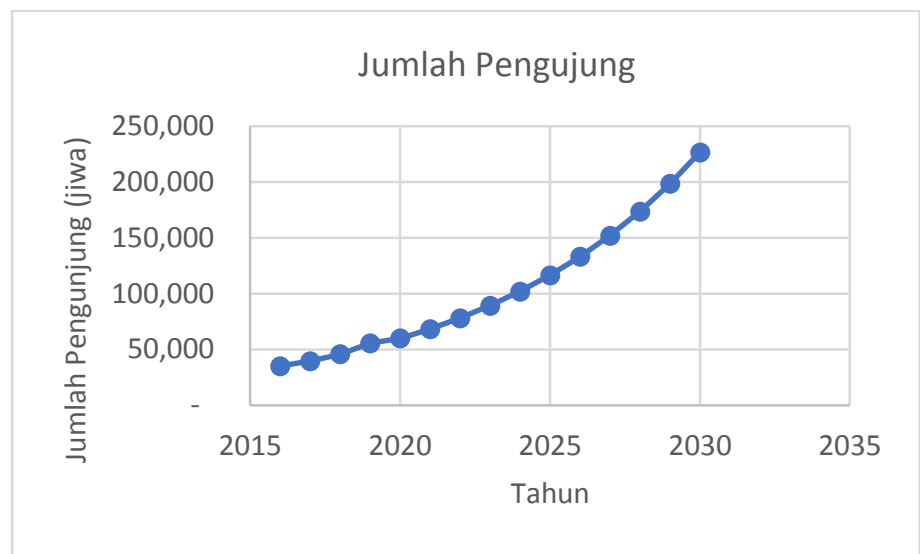

Gambar 3. Grafik Proyeksi Pengunjung 10 Tahun Kedepan

Sumber: Olahan Penulis

Berdasarkan analisis proyeksi pengunjung di kawasan wisata Bukit Panyaweuyan untuk 10 tahun ke depan diproyeksikan jumlah pengunjung adalah sebesar 226.512 jiwa dengan jumlah pengunjung tertinggi (high season) sekitar $4.530 \mathrm{jiwa} /$ weekend

\section{Rencana Penggunaan Lahan}

Pada penataan yang telah direncanakan, terdapat beberapa perubahan pada jenis penggunaan lahan yang terdapat di kawasan wisata Bukit Panyaweuyan. Perubahan yang dilakukan berdasarkan praturan dan jenis kegiatan yang sangat diperlukan untuk kawasan Bukit Panyaweuyan yakni perubahan jenis penggunaan lahan pada zona pertanian yang berdekatan dengan jalan utama akan di gunakan untuk pelebaran jalan sehingga para wisatawan dan masyarakat lebih dimudahkan. Berikut merupakan tabel 4 berisi jenis penggunaan lahan tersebut.

Tabel 4. Rencana Penggunaan Lahan

\begin{tabular}{ccc}
\hline Jenis Penggunaan Lahan & Luas (Ha) & Presentase (\%) \\
\hline Fasilitas & $1,59 \mathrm{Ha}$ & $4 \%$ \\
\hline RTH \& Sirkulasi & $2,32 \mathrm{Ha}$ & $6 \%$ \\
\hline Ladang / Pertanian & $27,20 \mathrm{Ha}$ & $69 \%$ \\
\hline Komersil & $3,48 \mathrm{Ha}$ & $9 \%$ \\
\hline Irigasi & $1,10 \mathrm{Ha}$ & $3 \%$ \\
\hline Hutan & $2,50 \mathrm{Ha}$ & $6 \%$ \\
\hline Hunian & $1,31 \mathrm{Ha}$ & $3 \%$ \\
\hline Total & $39,50 \mathrm{Ha}$ & $100 \%$ \\
\hline \multicolumn{3}{c}{ Sumber: Olahan penulis }
\end{tabular}

\section{KESIMPULAN DAN SARAN}

\section{Kesimpulan}

Kesimpulan yang diperoleh berdasarkan hasil penelitian ini adalah :

a. Bukit Panyaweuyan berada di Kawasan Pengembangan Pariwisata Provinsi ( KPPP) yang meliputi Kawasan Ekowisata alam pegunungan Majalengka - Kuningan dan sekitarnya. Di dalam RIPPARPROV ( Rencana Induk Pembangunan Pariwisata Provinsi Jawa Barat ) tahun 2015 - 2025, pada pasal 33 ( b) Kabupaten Majalengka termasuk dalam daya tarik wisata primer.

b. Bukit Panyaweuyan di dalam RTRW Kab. Majalengka Tahun 2011 - 2031 berada di Kawasan sistem Agribisnis dimana mempertahankan luas pertaniannya, pengembangan Kegiatan Wisata dengan memanfaatkan potensi alamnya. 
c. Bukit Panyaweuyan dibagi menajdi 3 zona yakni zona inti, zona penyangga dan zona pelayanan.

d. Bukit Panyaweuyan merupakan salah satu wisata yang memberikan pengalaman sekaligus edukasi terhadap wisatawan yang datang terkait tentang pertanian dan menjaga kelestarian alamnya dan budaya.

e. Masyarakat lokal Bukit Panyaweuyan memiliki kesempatan untuk menjadi pelaku dan penyedia jasa wisata, kegiatan wisata baru yang diusulkan hingga penyediaan akomodasi untuk wisatawan.

f. Perencanaan dan penataan kawasan wisata Bukit Panyaweuyan dilakukan dengan mengedepankan kelestarian alam dan perekonomian masyarakat sekitar sehingga ke dua aspek saling bersangkutan.

\section{Saran}

Saran yang dapat diberikan berdasarkan hasil penelitian ini adalah:

a. Masyarakat sekitar harus memanfaatkan lapangan pekerjaan yang tercipta dari terbentuknya kegiatan wisata baru di Bukit Panyaweuyan dengan optimal dan harus sadar akan pentingnya menjaga kelestarian alam sehingga wisata Bukit Panyaweuyan akan semakin terjaga dan berkelanjutan.

b. Pemerintah harus terus mendorong wisata Bukit Panyaweuyan sebagai salah satu wisata andalan Khususnya di Kabupaten Majalengka sehingga kegiatan pariwisata di Kawasan Bukit Panyaweuyan dan sekitarnya berkembang sehingga meningkatkan PAD ( Pendapatan Asli Daerah

c. Wisatawan ikut berperan dalam menjaga keberlangsungan Bukit Panyaweuyan dengan berkontrubusi dan berperilaku positif pada alam sekitar Bukit Panyaweuyan sebagai salah satu wujud menjaga kelestarian alam

\section{REFRENSI}

Bappenas. (2004). Tata Cara Pengembangan Kawasan Untuk Percepatan Pembangunan Daerah. Direktorat Pengembangan Kawasan Khusus dan Tertinggal, Bappenas: Jakarta.

Maruti, K.V. (2009). Agrotourism: scope and opportunities for the farmers in Maharashtra. Article Report. Dept. of Economics, Y.C. College. Pachwad Tal-Wai, Dist-Satara, State Maharashtra. 12. p. http://www.indiastat.com/article/09/kvm/fulltext.pdf. Downloaded on 9 February 2020.

Moore. (2005). Ekonomi pariwisata. Jakarta.

Suwardjo. (1986). Buku Pedoman Penyusunan Pola Rehabilitasi Lahan dan Konversi Tanah. 